\title{
BAYES STATISTICAL DECISIONS WITH RANDOM FUZZY DATA - AN APPLICATION FOR THE WEIBULL DISTRIBUTION
}

\section{ROZMYTO-BAYESOWSKI MODEL PODEJMOWANIA DECYZJI STATYSTYCZNYCH - ZASTOSOWANIE DO ROZKŁADU WEIULLA}

\begin{abstract}
In the majority of decision models used in practice all input data are assumed to be precise. This assumption is made both for random results of measurements, and for constant parameters such as, e.g. costs related to decisions. In reality many of these values are reported in an imprecise way. When this imprecision cannot be related to randomness the fuzzy set theory yields tools for its description. It seems to be important to retain both types of uncertainty, random and fuzzy, while building mathematical models for making decisions. In the paper we propose a fuzzy-Bayesian model for making statistical decisions. In the proposed model the randomness of data is reflected in related risks, and fuzziness is described by possibility measures of dominance such as PSD (Possibility of Strict Dominance) and NSD (Necessity of Strict Dominance). The proposed model allows a decision-maker to reflect in his/hers decisions different types of uncertainty. The theoretical results have been applied in the case of reliability data described by the Weibull distribution.
\end{abstract}

Keywords: Bayesian statistics, fuzzy data, possibility measures, reliability, Weibull distribution.

\begin{abstract}
W większości stosowanych w praktyce modeli decyzyjnych zaktada się, że wszystkie wystęujące w nich dane wejściowe sa podane w sposób precyzyjny. Założenie to dotyczy zarówno losowych wyników pomiarów jak też $i$ stałych parametrów, takich jak $n p$. koszty podjętych decyzji. W rzeczywistości wiele z tych wartości jest podawanych w sposób nieprecyzyjny. Jeżeli taki brak precyzji nie ma charakteru losowego, to teoria zbiorów rozmytych dostarcza narzędzi do opisu tego zjawiska. Wydaje się rzecza istotna, by przy tworzeniu matematycznych modeli podejmowania decyzji zachować oba typy niepewności: losowość i rozmytość. W pracy proponujemy rozmyto-bayesowski model podejmowania decyzji statystycznych. W proponowanym modelu losowość odpowiada za zwiazane z podjęciem decyzji ryzyko, zaś rozmytość jest opisana przez miary możliwości dominacji, takie jak PSD (Możliwość Ścisłej Dominacji) oraz NSD (Konieczność Ścistej Dominacji). Zaproponowany model pozwala decydentowi ująć w procesie podejmowania decyzji różne rodzaje niepewności. Rozważania teoretyczne zostały w pracy zastosowane do analizy danych niezawodnościowych opisanych rozktadem Weibulla.
\end{abstract}

Stowa kluczowe: statystyka bayesowska, dane rozmyte, miary możliwości, niezawodność, rozkład Weibulla.

\section{Introduction}

Testing statistical hypotheses is one of the most important parts of statistical inference. On the other hand it can be regarded as a part of the decision theory. In the decision theory we assume that decisions (actions belonging to a certain action space) should depend upon a certain state which is uncontrollable and unknown for a decision maker. We usually assume that unknown states are generated by random mechanisms. However, all we could know about these mechanisms is their description in terms of the probability distribution $P_{\theta}$ that belongs to a family of distributions $\left\{P_{\theta}: \theta \in \Theta\right\}$ indexed by a parameter $\theta$ (one or multidimensional). In such a case a state space is often understood as equivalent to the parameter space $\Theta$. If we knew the true value of $\theta$ we would be able to take a correct decision. The choice of an appropriate decision depends upon a value of a certain utility function that has to be defined on the product of the action space and the state space. If we had known the unknown state we would have been able to choose the most preferred action looking for the action with the highest value of the assigned utility. In practice, we define the expected reward (or the loss) associated with the given action for the given state $\theta \in \Theta$, and then we define the utility $u \in U$ that 'measures' the preference the decision maker assigns to that reward (loss).

In the Bayesian setting of the decision theory we assume that there exists prior information about the true state, and that this information is expressed in terms of the probability distribution $\pi(\theta)$ defined on the parameter space $\Theta$. By doing this we identify each action with probability distribution on a set of possible utilities $U$. According to the Bayesian decisions paradigm we choose the action with the highest value of the expected utility, where expectation is calculated with respect to the probability distribution defined on $U$.

When a decision maker has an opportunity to observe a random variable (or a random vector) $X$ that is related to the state $\theta$, such an observation provides him additional information which may be helpful in making proper decisions. In such a case the decision problem is called the statistical decision problem. Comprehensive presentation of the Bayesian decision theory is given in a classical textbook of Raiffa and Schleifer [24], and the Bayesian approach to statistical decision problems may be found in DeGroot [5].

In the statistical decision theory we deal with many quantities which may be vague and imprecise. First, our observation may be imprecise, described in linguistic terms. In such a case we deal with 
imprecise (fuzzy) statistical data. Many books and papers have been written on the statistical analysis of fuzzy data. Classical problems of statistical decisions with fuzzy data have been discussed, e.g., in the paper by Grzegorzewski and Hryniewicz [13]. More general approaches, referring to different concepts of fuzzy randomness, are presented in an overview paper by Gil and Hryniewicz [11]. First results presenting the Bayesian decision analysis for imprecise data were given in papers by Casals et al. [2, 3]. In these papers the authors described fuzzy observations using the notion of the fuzzy information system introduced by Zadeh [29] and Tanaka et al. [26]. Other approach, based on the concept of imprecise numbers, has been proposed by Viertl [27]. Further results concerning the decisions based on fuzzy statistical information have been published by Casals [1] and Gil and Lopez-Diaz [12]. Imprecise information about the parameters of the prior distribution have been considered in Hryniewicz [14] and Frühwirth-Schnatter [10]. In the statistical decision theory we may also face practical problems when verified hypotheses are imprecise. This problem was considered by Delgado et al. [6] and by Casals [1]. Finally, the loss function (or the utility function) may be expressed in a fuzzy way, as in the paper by Gil and Lopez-Diaz [12]. Original results on Bayes fuzzy hypotheses testing have been also presented by Taheri and Behboodian [25] who proposed another approach using the posterior odds ratio as the criterion for decision making.

The crucial problem of the fuzzy approach to the Bayes statistical decision analysis is to compare fuzzy risks related to considered decisions. This problem arises from the fact that fuzzy numbers that describe fuzzy risks are not naturally ordered. Thus, the decisions depend upon the method used for such an ordering. Theory of possibility, introduced by Zadeh [29], and based on the fuzzy logic, provides tools for making decisions in the fuzzy environment. We propose to use the possibilistic Necessity of Strict Dominance Index (NSD) introduced by Dubois and Prade [8]. Theoretical results are presented in the second, third and fourth sections of the paper. The fifth section is devoted to the application of the proposed methodology for the case of reliability data described by the Weibull distribution.

\section{Calculation of the Bayes risks in crisp environment}

In the Bayesian approach to statistical decisions we take into consideration potential losses and rewards associated with each considered decision. Let $\theta \in \Theta$ be a parameter describing an element of the state space, and $\delta \in \Delta$ be a decision (action) from a space of possible (admissible) decisions. In the general case of making decisions we usually define a utility function $u(\theta, \delta)$ which assigns a certain utility $u \in U$ to the decision $\delta$ which describes a decision maker's level of preference for the decision $\delta$ if the true state is described by $\theta$.

However, in statistical decisions we rather consider the loss $l(\theta, \delta)$ assigned to decision $\delta$ if the true state is described by $\theta$.

Assume now that the decision maker knows the likelihood function $L(\mathbf{x} \mid \theta)=L\left(x_{1}, \ldots, x_{n} \mid \theta\right)$ that summarizes the observations of a random sample $\left(X_{1}, \ldots, X_{n}\right)$. Moreover, we assume that the decision maker has some prior information about possible values of $\theta$. This information, according to the Bayes decision theory is represented by

the prior probability distribution $\pi(\theta)$. This information is merged with the information yielded by the random sample. The updated information about the true value of the state $\theta$ is calculated using the Bayes theorem, and expressed in the form of the posterior probability distribution:

$$
g(\theta \mid \mathbf{x})=\frac{L(\mathbf{x} \mid \theta) \pi(\theta)}{\int_{\Theta} L(\mathbf{x} \mid \theta) d \pi(\theta)}=\frac{g_{n}(\theta \mid \mathbf{x})}{n(\mathbf{x})}
$$

where $\mathbf{x}=\left(x_{1}, \ldots, x_{n}\right)$, and $g_{n}(\mathbf{x} \mid \theta)$ is the non-normalised posterior distribution. Further analysis is performed in exactly the same way with the posterior probability distribution $g(\theta \mid \mathbf{x})$ replacing the prior probability distribution $\pi(\theta)$.

Let $\delta(\mathbf{x})=\delta\left(x_{1}, \ldots, x_{n}\right)$ be a decision function which is used for choosing an appropriate decision for given sample values $\left(x_{1}, \ldots, x_{n}\right)$. The risk function, interpreted as an expected loss incurred by the decision $\delta$, is calculated as:

$$
\rho(\delta)=\int_{\Theta} \int_{X} l\left(\theta, \delta\left(x_{1}, \ldots, x_{n}\right)\right) f\left(x_{1}, \ldots, x_{n} \mid \theta\right) \pi(\theta) d \mathbf{x} d \theta
$$

Let $\Delta$ be the space of possible decision functions. Function $\delta^{*}$ that fulfils the following condition:

$$
\rho\left(\delta^{*}\right)=\inf _{\delta \in \Delta} \rho(\delta)
$$

we call the Bayes decision function, and the corresponding risk $\rho\left(\delta^{*}\right)$ we call the Bayes risk. Statistical decisions with the risk equal to the Bayes risk are called optimal. In this paper we restrict ourselves to a particular problem of the Bayes decisions, namely to the Bayes test of statistical hypothesis $H_{0}: \theta \in \Theta_{0}$ against the alternative hypothesis $H_{1}: \theta \in \Theta_{1}$, where $\Theta_{0}$ and $\Theta_{1}$ are the subsets of the state space $\Theta$ such that $\Theta_{0} \cap \Theta_{1}=\varnothing$. Let us define two functions:

$$
H_{0}(\theta)=\left\{\begin{array}{ll}
1, & \theta \in \Theta_{0} \\
0, & \theta \in \Theta_{1}
\end{array} \text { and } H_{1}(\theta)=\left\{\begin{array}{ll}
0, & \theta \in \Theta_{0} \\
1, & \theta \in \Theta_{1}
\end{array}\right. \text {. }\right.
$$

Now, let us define loss functions:

$$
u\left(\theta, a_{0}\right)=a(\theta)\left[1-H_{0}(\theta)\right]
$$

that describes the loss related to the acceptance of $H_{0}$, and

$$
u\left(\theta, a_{1}\right)=b(\theta)\left[1-H_{1}(\theta)\right]
$$

that describes the loss related to the acceptance of $H_{1}$. Functions $a(\theta)$ and $b(\theta)$ are two arbitrary nonnegative functions. In such a case we may consider only two risks: the risk of accepting $H_{1}$ when $H_{0}$ is true given by:

$$
R_{1}=\int_{\Theta_{1}} u\left(\theta, a_{1}\right) g(\theta \mid \mathbf{x}) d \theta,
$$

and the risk of accepting $H_{0}$ when $H_{1}$ is true given by:

$$
R_{0}=\int_{\Theta_{0}} u\left(\theta, a_{0}\right) g(\theta \mid \mathbf{x}) d \theta .
$$

In the following section we present methods for the computation of such a risk in different cases representing situations when different parts of the decision model are described in an imprecise way. 


\section{Bayes risks for fuzzy statistical data and fuzzy prior information}

Let us consider situation when available statistical data are vague and are described by fuzzy random variables. The notion of a fuzzy random variable has been defined by many authors in a different way. One of these definitions, attributed to Kwakernaak [20,21] and - independently - Kruse (see, e.g. Kruse and Meyer [19] for more information), considers the fuzzy random variable $\tilde{X}$ as a fuzzy (vague) perception of an unknown ordinary random variable $X: \Omega \rightarrow R$, called an original of $\tilde{X}$. In the presence of fuzzy statistical data the posterior distribution of the state variable $\theta$ can be obtained by the application of Zadeh's extension principle to (1). Let $\tilde{x}_{i}^{\alpha}=\left(\tilde{x}_{i, L}^{\alpha}, \tilde{x}_{i, U}^{\alpha}\right), i=1, \ldots, n$ be the $\alpha$-cuts of the fuzzy observations $\tilde{x}_{1}, \ldots, \tilde{x}_{n}$. Following Frühwirth-Schnatter [10] let's denote by $C(\tilde{\mathbf{x}})_{\alpha}$ the $\alpha$-cut of the fuzzy sample which is equal to the Cartesian product of the $\alpha$-cuts $\tilde{x}_{1}^{\alpha}, \ldots, \tilde{x}_{n}^{\alpha}$. Frühwirth-Schnatter [10] also proposed a generalization of the fuzzy risk model by allowing fuzziness in the description of the prior information. In such case the probability density function $\pi(\theta, \eta)$ that describes the prior knowledge about the values of the state variable $\theta$ may be described as the function of fuzzy parameters $\tilde{\eta}$ denoted by $\pi(\theta, \tilde{\eta})$. Let us denote $\alpha$-cut of the fuzzy vector $\tilde{\eta}$ by $C(\eta)_{\alpha}$. Thus, the $\alpha$-contours of the fuzzy posterior probability density are now given by (see [10]):

$$
\begin{aligned}
& g_{\alpha}^{L}(\theta)=\min _{\mathbf{x}, \eta \in C(\tilde{\mathbf{x}})_{\alpha} \times C(\tilde{\eta})_{\alpha}} \frac{f(\mathbf{x} \mid \theta) \pi(\theta, \eta)}{n(\theta, \eta)} \\
& g_{\alpha}^{U}(\theta)=\max _{\mathbf{x}, \eta \in C(\tilde{\mathbf{x}})_{\alpha} \times C(\tilde{\eta})_{\alpha}} \frac{f(\mathbf{x} \mid \theta) \pi(\theta, \eta)}{n(\theta, \eta)}
\end{aligned}
$$

where $n(\theta, \eta)$ is a normalizing constant. Having these $\alpha$-contours we can the general methodology for integrating fuzzy functions presented in Dubois and Prade [7] compute the membership functions of fuz-

zy risks $\tilde{\mathbf{R}}_{0}$ and $\tilde{\mathbf{R}}_{1}$. Let us denote by $C\left(\tilde{R}_{h}\right)_{\alpha}=\left(\tilde{R}_{h}^{\alpha, L}, \tilde{R}_{h}^{\alpha, L}\right)$ the $\alpha$-cuts of the fuzzy risks $\tilde{R}_{h}, h=0,1$. The lower and upper bounds of these $\alpha$-cuts are now calculated from the following formulae:

$$
\begin{aligned}
& R_{h}^{\alpha, L}=\int_{\Theta_{h}} L\left(\theta, a_{h}\right) g_{\alpha}^{L}(\theta) d \theta, h=0,1 \\
& R_{h}^{\alpha, U}=\int_{\Theta_{h}} L\left(\theta, a_{h}\right) g_{\alpha}^{U}(\theta) d \theta, h=0,1
\end{aligned}
$$

The knowledge of these $\alpha$-cuts is thus equivalent to the knowledge of the membership functions of fuzzy risks $\tilde{R}_{0}$ and $\tilde{R}_{1}$, respectively. Further generalization may be achieved by assuming a vague character of utilities (losses). The procedure for finding the $\alpha$-cuts of $\tilde{\mathbf{R}}_{0}$ and $\tilde{\mathbf{R}}_{1}$ is similar, and described in Hryniewicz [15].

Some authors (see, e.g., Viertl [27]) consider lower and upper envelopes for prior and posterior densities. However, such envelopes do not have probabilistic interpretation, as they do not integrate to one (only to "approximately one", as it was stated in Viertl and Hareter
[28]. This, unacceptable for many researchers, feature is the consequence of a fact that probability density functions cannot be ordered (in contrast to, e.g., cumulative probability functions, expected values, etc.), and the choice of their „lower” or ,upper” representatives requires some additional assumptions. Therefore, the further usage of these envelopes in the Bayesian analysis seems to be debatable.

\section{Bayes risks in case of fuzzy statistical hypotheses}

In this subsection we present a method proposed in Hryniewicz [15] for the computation of fuzzy risks related to the test of the fuzzy hypothesis $\tilde{H}_{0}$ against a fuzzy alternative $\tilde{H}_{1}$. First, let us suppose that all remaining information (i.e. statistical data, prior information, and loss functions) are crisp.

Let $\tilde{H}_{h}: \theta \in \tilde{\Theta}_{h}, h=0,1$ be considered fuzzy statistical hypotheses, where $\tilde{\Theta}_{h}, h=0,1$ are the fuzzy sets described by their membership functions $\mu_{\Theta_{h}}(\theta)$. To simplify the problem let us assume that each fuzzy set $\tilde{\Theta}_{h}$ may be presented in a form of a fuzzy interval $\left(\tilde{\Theta}_{L, h}, \tilde{\Theta}_{U, h}\right)$, where fuzzy sets $\tilde{\Theta}_{L, h}$ and $\tilde{\Theta}_{U, h}$ have the $\alpha$-cuts $\left(\Theta_{L, h}^{\alpha, l}, \Theta_{L, h}^{\alpha, U}\right)$ and $\left(\Theta_{U, h}^{\alpha, l}, \Theta_{U, h}^{\alpha, U}\right)$ such that $\Theta_{L, h}^{\alpha, l} \leq \Theta_{U, h}^{\alpha, l}$, and $\Theta_{L, h}^{\alpha, u} \leq \Theta_{U, h}^{\alpha, u}$. Denote the membership functions of $\tilde{\Theta}_{L, h}$ and $\tilde{\Theta}_{U, h}$ as $\mu_{L, h}$ and $\mu_{U, h}$, respectively. Using the notation of Dubois and Prade [7] we may write the membership functions of the fuzzy risks $\tilde{\mathbf{R}}_{h}, h=0,1$ as:

$$
\mu_{\tilde{\mathbf{R}}_{h}}(t)=\sup _{y, z: t=\int_{u}^{w} u\left(\theta, \alpha_{h}\right) g(\theta \mid \mathbf{x}) d \theta} \min \left[\mu_{L, h}(y), \mu_{U, h}(z)\right]
$$

Finally, let us consider the most general case when we deal with fuzzy statistical data, fuzzy prior information, fuzzy loss function, and fuzzy statistical hypotheses. In this case the fuzzy risks $\tilde{\mathbf{R}}_{h}, h=0,1$ are given as an integrals over fuzzy sets from fuzzy functions, i.e.

$$
\tilde{\mathbf{R}}_{h}=\int_{\tilde{\Theta}_{h}} \tilde{u}\left(\theta, a_{h}\right) \tilde{g}(\theta \mid \tilde{\mathbf{x}}) d \theta .
$$

Such a fuzzy integral is practically impossible to calculate. However, Hryniewicz [15] proposed its reasonable approximation form above using the following formulae:

$$
\begin{gathered}
\mathbf{R}_{h}^{\alpha, L}=\int_{\Theta_{L, h}^{\alpha, l}}^{\Theta_{U, h}^{\alpha, u}} L_{\alpha}^{L}\left(\theta, a_{h}\right) g_{\alpha}^{L}(\theta \mid \mathbf{x}) d \theta, \\
\mathbf{R}_{h}^{\alpha, U}=\int_{\Theta_{L, h}^{\alpha, l}}^{\Theta_{U, h}^{\alpha, u}} L_{\alpha}^{U}\left(\theta, a_{h}\right) g_{\alpha}^{U}(\theta \mid \mathbf{x}) d \theta .
\end{gathered}
$$

When only two hypotheses are considered we have to deal with a relatively simple problem of comparing two fuzzy numbers $\tilde{\mathbf{R}}_{0}$ and $\tilde{\mathbf{R}}_{1}$. For doing this comparison Hryniewicz [15] proposed a possibilistic approach introduced by Dubois and Prade [8]. To compare these fuzzy risks he proposed to use the concept of the Necessity of Strict Domi- 
nance Index $(N S D)$ and Possibility of Dominance Index $(P D)$. The $P D$ index is defined for two fuzzy sets $\tilde{A}$ and $\tilde{B}$ as:

$$
P D=\operatorname{Poss}(\tilde{A} \geq \tilde{B})=\sup _{x, y: x \geq y} \min \left\{\mu_{A}(x), \mu_{B}(y)\right\}
$$

where $\mu_{A}(x)$ and $\mu_{B}(y)$ are the membership functions of $\tilde{A}$ and $\tilde{B}$, respectively. $P D$ is the measure for a possibility that the set $\tilde{A}$ is not dominated by the set $\tilde{B}$. The NSD index is defined as:

$$
N S D=\operatorname{Ness}(\tilde{A}>\tilde{B})=1-\sup _{x, y: x \leq y} \min \left\{\mu_{A}(x), \mu_{B}(y)\right\} .
$$

$N S D$ represents necessity that the set $\tilde{A}$ dominates the set $\tilde{B}$. If $N S D>0$ there exists a strong indication of the acceptance of one hypothesis (say $\tilde{A}$ ) over another one (say $\tilde{B}$ ).

Possibilistic indices mentioned above can be used in the evaluation of the undertaken decision in terms of preferences. Cutello and Montero [4] proposed three measures of preference relations. Let be

the measure of indifference between alternatives $x$ and $y, \mu_{B}(x, y)$ be the measure that the alternative $x$ is better than the alternative $y$,

$\mu_{W}(x, y)$ be the measure that the alternative $x$ is worse than the alternative $y$. Hryniewicz [15] has noted that in the context of statistical decisions we have the following relations:

$$
\begin{gathered}
\mu_{I}(x, y)=P D-N S D \\
\mu_{B}(x, y)=N S D \\
\mu_{W}(x, y)=1-P D .
\end{gathered}
$$

In the next section we show a simple example of this methodology for the case of the lifetime data described by the Weibull distribution.

\section{Testing hypotheses for the Weibull distribution using imprecise information}

Let $X$ be the random variable describing lifetime data. The Weibull distribution, defined by the probability density function (pdf):

$$
f(x \mid \gamma, s)=\frac{s x^{s-1}}{\gamma \exp \left(x^{s} / \gamma\right)}, x>0, s>0, \gamma>0
$$

is frequently used for modeling such data. The parameter $s$ determines the shape of the pdf function, and the parameter $\gamma$ determines the spread of variability of $X$. Because of its great applicability in the analysis of reliability (or survival, in a more general setting) classical (non-Bayesian) methods of statistical analysis for the Weibull distribution have been developed by many authors. For more detailed information the reader can be directed to many textbooks, such as e.g. the book by Lawless [22]. The number of papers devoted to the problem of the Bayesian analysis of the lifetime data described by the Weibull distribution is not so high because of difficulties with finding analytical solutions. Comprehensive bibliography of the problem together can be found in the recent paper by Fernández [9]. The rea- son of these problems stems from the fact that the bivariate conjugate prior distribution for both parameters of the Weibull distribution does not exist. Therefore, indirect methods, such as the method proposed by Kaminskiy and Krivtsov [17], have to be used.

The problem of the statistical analysis of data described by the Weibull distribution becomes much easier if the value of the shape parameter is $s$ known. In such case the random variable $Y=X^{s}$ is distributed exponentially with the scale parameter equal to $\gamma$. Statistical analysis of lifetime data described by the exponential distribution is well developed, both in the classical (non-Bayesian) and Bayesian sense. For example, in the case of Bayesian there exists the conjugate prior probability distribution for the scale parameter $\gamma$. This is the inverted gamma distribution defined by the following pdf function:

$$
g(y)=\frac{a^{b} \exp (-a / \gamma)}{\Gamma(b) \gamma^{b+1}}, \gamma>0, a>0, b>0 .
$$

Note, that the prior distribution for the inverse of the scale distribution $\lambda=1 / \gamma$ is the well known gamma distribution with the same parameters $a$ and $b$, respectively. Moreover, in case of the exponential distribution there exists sufficient statistic that summarizes available statistical data. For example in case of type-II censoring this statistic is given by $(w(y), r)$, where $w(y)=\sum_{i=1}^{r} y_{(i)}+(n-r) y_{(r)}$, and $y_{(1)} \leq y_{(2)} \leq \cdots \leq y_{(r)}$. The posterior distribution of $\gamma$ is also the inverted gamma distribution with parameters $a^{\prime}=a+w(y)$ and $b^{\prime}=b+r$.

Now let's consider the case that we have only partial knowledge about the value of the shape parameter $s$. Formal description of partial knowledge is still the subject of controversies. Some researchers claim that classical probabilities are sufficient in this case. However, many other researchers present counterexamples showing that some other methods, like imprecise probabilities, Dempster-Shafer belief functions, p-boxes, possibility distributions etc., should be used in order to capture the essence of partial knowledge. In this paper we assume that our knowledge about the value of $s$ is described by a possibility distribution, which from a formal point of view is equivalent to the membership function $\mu(s)$ of a fuzzy number $\tilde{s}$. Thus, we assume that we analyze a fuzzy random variable defined as:

$$
\tilde{Y}=X^{\tilde{s}}
$$

and the sample information is presented as the fuzzy number:

$$
\tilde{w}(y)=\sum_{i=1}^{r} \tilde{y}_{(i)}+(n-r) \tilde{y}_{(r)} .
$$

Therefore, all results of statistical analyses, either Bayesian or nonBayesian, will be presented using terms related to fuzzy sets.

Let us consider the problem of the Bayesian estimation of the parameter $\gamma$ in case of type-II censored lifetime data. As natural Bayesian estimators can be considered such statistics like the mode of the posterior distribution or its median. In case of the known $s$ it can be done by solving nonlinear equations (see [9]). However, when we have fuzzy data in the form of $\tilde{w}(y)$ this task is rather difficult to do. Much simpler result can be obtained when we use a decision-theoretic approach. When the losses due to erroneous estimation are proportional to $\left(\gamma_{B}-\gamma\right)^{2}$ then the optimal estimator that minimizes the Bayesian risk is equal to the expected value in the posterior distribution, and in the case of fuzzy data is given by a very simple formula: 


$$
\tilde{\gamma}_{B}=\frac{a+\tilde{w}(y)}{b+r-1}, b+r>1
$$

The membership function of $\tilde{\gamma}_{B}$ is similar to the membership function of $\tilde{w}(y)$, except for a linear transformation of the $\mathrm{x}$-axis.

Acquisition of the parameters of the prior distribution is the most important practical problem of the Bayesian approach to statistics. Usually, an expert proposes his/hers evaluations of the moments of the prior distribution, and these values are set equal to their theoretical counterparts, forming equations the parameters of the prior distribution are calculated from. Implementation of this practice in the considered case is rather questionable, as the parameter $\gamma$ does not have any direct interpretation. Therefore such equations should be constructed using information that is directly related to observed lifetimes or other reliability indices.

The first two moments of the prior distribution of reliability characteristics, such as the reliability function $R(t)$ or the hazard function $h(t)=h_{t}$, are sometimes recommended for setting the parameters of the prior distribution. In the case of the hazard function $h_{t}$ Fernández [9] shows that the expected value of the prior distribution of this index is given by $E=E\left[h_{t}\right]=s b t^{s-1} / a$, and its variance is given by $V=V\left[h_{t}\right]=s^{2} b t^{2 s-21} / a^{2}$. By solving these two equations we can easily find closed formulae for the calculation of $a$ and $b$ :

$$
\begin{gathered}
a=a(s)=s t^{s-1} \frac{E}{V} \\
b=\frac{E^{2}}{V} .
\end{gathered}
$$

Hence, the Bayes estimator of $\gamma$ is given as:

$$
\gamma(s)=\frac{a(s)+\sum_{i=1}^{r} x_{(i)}^{s}+(n-r) x_{(r)}^{s}}{b+r-1} .
$$

However, in the considered case of the fuzzy information about the value of $s$ the Bayes estimator of $\gamma$ will be described by (29) with $s$ replaced by fuzzy $\tilde{s}$.

Let $\left(s_{L}^{\alpha}, s_{U}^{\alpha}\right)$ be the $\alpha$-cut of the fuzzy variable $\tilde{s}$ that represents imprecise information about the value of the shape parameter $s$. We can find the limiting values of the $\alpha$-cut of the Bayesian estimator of the parameter $\gamma$ by solving the following optimization problems:

$$
\begin{gathered}
\gamma_{B, L}^{\alpha}=\inf _{s \in\left(s_{L}^{\alpha}, s_{U}^{\alpha}\right)} \gamma(s) \\
\gamma_{B, U}^{\alpha}=\sup _{s \in\left(s_{L}^{\alpha}, s_{U}^{\alpha}\right)} \gamma(s) .
\end{gathered}
$$

Unfortunately, $\gamma(s)$ is not a monotonic function of $s$. However, for consistent possible values of $s$ (either not greater than one or not smaller than one), and usually observed values of $x$ 's (smaller than the expected value) $\gamma(s)$ is monotonic. Thus, finding the limiting values according to (27) and (28) does not require special computational efforts.

In a similar, but more complicated, way one can calculated fuzzy risks related to statistical hypotheses about $\gamma$ and its different functions such as reliability function or hazard rate. For example, consider the important from a practical point of view characteristics such as the reliable life $t_{R}$, defined as:

$$
t_{R}=(-\gamma \ln R)^{1 / s}
$$

where $R$ is a specified fraction of survived objects. The Bayes estimator of tR in the case of the gamma prior distribution for $\lambda=1 / \gamma$ with the scale parameter $a_{0}=1 / a$ and the shape parameter $b_{0}=b$, is given in Martz and Waller[23] as follows:

$$
t_{R, B}=\frac{\Gamma\left(b_{0}+r-1 / s\right)(-\ln R)^{1 / s}}{\Gamma\left(b_{0}+r\right)\left[a_{0} /\left(a_{0} w(y)+1\right)\right]^{1 / s}} .
$$

Taking into account the imprecise information about the shape parameter $s$, and hence, the imprecise values of the parameter $a$, the limiting values of the $\alpha$-cut of the fuzzy Bayes estimate of the reliable life are given by the formulae:

$$
t_{R, B, L}^{\alpha}=\inf _{s \in\left(s_{L}^{\alpha}, s_{U}^{\alpha}\right)} \frac{\Gamma(b+r-1 / s)(-\ln R)^{1 / s}}{\Gamma(b+r)} \frac{[a(s)]^{1 / s}}{\left[a^{-1}(s)\left(\sum_{i=1}^{r} x_{(i)}^{s}+(n-r) x_{(r)}^{s}\right)+1\right]^{1 / s}},
$$

$$
t_{R, B, U}^{\alpha}=\sup _{s \in\left(s_{L}^{\alpha}, s_{U}^{\alpha}\right)} \frac{\Gamma(b+r-1 / s)(-\ln R)^{1 / s}}{\Gamma(b+r)} \frac{[a(s)]^{1 / s}}{\left[a^{-1}(s)\left(\sum_{i=1}^{r} x_{(i)}^{s}+(n-r) x_{(r)}^{s}\right)+1\right]^{1 / s}} .
$$

These values can be computed only numerically using widely accessible routines for finding minima and maxima of continuous functions.

Knowing the fuzzy Bayes estimates of reliability characteristics we can relatively easily find the fuzzy Bayes confidence intervals for these characteristics. In order to do so we have to replace in the respective formulae, that can be found e.g. in the book by Martz and Waller [23], the values of the non-fuzzy estimator with the respective limiting values of the $\alpha$-cuts: the lower value of the $\alpha$-cut in the formula for the lower limit of the Bayes confidence interval, and the upper of the $\alpha$-cut in the formula for the upper limit of the Bayes confidence interval. For the known value of $s$ the limits of the confidence intervals are given by the following formulae:

$$
\begin{aligned}
& \bar{t}_{R, B}(\gamma)=(-\ln R)^{1 / s}\left\{\frac{a^{-1}(s) \chi_{\gamma / 2}^{2}(2 r+2 b)}{2 a^{-1}(s)\left[\sum_{i=1}^{r} x_{(i)}^{s}+(n-r) x_{(r)}^{s}\right]+2}\right\}^{1 / s}, \\
& \underline{t}_{R, B}(\gamma)=(-\ln R)^{1 / s}\left\{\frac{a^{-1}(s) \chi_{1-\gamma / 2}^{2}(2 r+2 b)}{2 a^{-1}(s)\left[\sum_{i=1}^{r} x_{(i)}^{s}+(n-r) x_{(r)}^{s}\right]+2}\right\}^{1 / s},
\end{aligned}
$$


where $\chi_{\beta}^{2}(k)$ is the quantile of order $\beta$ from the chi-square distribution with $k$ degrees of freedom. When the shape parameter $s$ is fuzzy the Bayes confidence interval defined by the limiting values (35) and (36) also becomes fuzzy. Its $\alpha$-cut is in this case defined by the following limiting values:

$$
\begin{aligned}
& t_{R, B}^{\alpha}(\gamma)=\inf _{s \in\left(s_{L}^{\alpha}, s_{U}^{\alpha}\right)} \underline{t}_{R, B}(\gamma), \\
& \bar{t}_{R, B}^{\alpha}(\gamma)=\sup _{s \in\left(s_{L}^{\alpha}, s_{U}^{\alpha}\right)} \bar{t}_{R, B}(\gamma) .
\end{aligned}
$$

The nested $\alpha$-cuts (for all $\alpha \in(0,1]$ ) may be regarded as the possibility distribution of the fuzzy Bayes reliable life $\tilde{t}_{R, B}$. Then, we can use the possibilistic methodology described in the fourth section of this paper to compare the fuzzy limits of the Bayes confidence intervals with the reliability requirements for $t_{R}$.

\section{Conclusions}

Statistical methods that use the Bayes approach for the analysis of data are of special importance in the theory and practice of reliability. Because of high reliability of contemporary systems and their elements it is difficult to collect enough data for precise estimation of reliability characteristics using classical statistical methods. Therefore, it is necessary to utilize additional information represented in the form of prior distributions of parameters of the probability distribution of life times. However, it is usually difficult to represent our prior knowledge in a fully precise way. Moreover, the statistical data may be also reported imprecisely. Thus, we should have the methodology for combining random uncertainty with non-random (fuzzy) imprecision in the context of the Bayes reliability analysis. In this paper we have presented a possibilistic approach for making decisions in the case of the fuzzy Bayes reliability analysis.

The results obtained in this paper for the case of the Weibull distribution can be applied not only in the context of reliability. This probability distribution is used for the description of extreme events, and has been also applied in the analysis of some environmental phenomena. In that particular context the combination of imperfectly reported data with imprecise opinions provided by experts is of great practical importance. Therefore, the results presented in this paper can be applied also in this area.

\section{Acknowledgment}

The work on this paper has been partially supported by the grant No. N N519316735 of the Polish Ministry of Science and Higher Education.

\section{References}

1. Casals M.R. Bayesian testing of fuzzy parametric hypotheses from fuzzy information. RAIRO, Operations Research 1993; 27: 189-199.

2. Casals M.R., Gil M.A., Gil P. On the use of Zadeh's probabilistic definition for testing statistical hypotheses from fuzzy information. Fuzzy Sets and Systems 1986; 20: 175-190, http://dx.doi.org/10.1016/0165-0114(86)90076-X.

3. Casals M.R., Gil M.A., Gil P. The Fuzzy Decision Problem: an approach to the Problem of Testing Statistical Hypotheses with Fuzzy Information. European Journal of Operational Research 1986; 27: 371-382, http://dx.doi.org/10.1016/0377-2217(86)90333-4.

4. Cutello V., Montero J. An Extension of the Axioms of Utility Theory Based on Fuzzy Rationality Measures. In: Fodor J., De Baets B., Perny P. (Eds.) Preference and Decisions under Incomplete Knowledge. Heidelberg: Physica-Verlag, 1999, 33 - 50.

5. De Groot M.H. Optimal Statistical Decisions. New York: McGraw Hill, 1970.

6. Delgado M., Verdegay J.L., Vila M.A. Testing fuzzy hypotheses. A Bayesian approach. In: Gupta M.M., Kandel A., Bandler W., Kiszka J.B. (Eds.) Approximate Reasoning in Expert Systems. Amsterdam: Elsevier, 1985, 307-316.

7. Dubois D., Prade H. Fuzzy Sets and Systems. Theory and Applications. New York: Academic Press, 1980.

8. Dubois D., Prade H. Ranking fuzzy numbers in the setting of possibility theory. Information Sciences 1983; 3: 184-244, http://dx.doi. org/10.1016/0020-0255(83)90025-7.

9. Fernández A.J. Weibull inference using trimmed samples and prior information. Statistical Papers 2009; 50: 119-136, http://dx.doi. org/10.1007/s00362-007-0067-2.

10. Frühwirth-Schnatter S. Fuzzy Bayesian inference. Fuzzy Sets and Systems 1993; 60: 41-58, http://dx.doi.org/10.1016/01650114(93)90288-S.

11. Gil M.A., Hryniewicz O. Statistics with Imprecise Data. In: Meyers R. A. (Ed.) Encyclopedia of Complexity and Systems Science. Heidelberg: Springer, 2009, 8679-8690.

12. Gil M.A., Lopez-Diaz M. Fundamentals and Bayesian Analyses of Decision Problems with Fuzzy-Valued Utilities. International Journal of Approximate Reasoning 1996; 15: 203-224, http://dx.doi.org/10.1016/S0888-613X(96)00073-4.

13. Grzegorzewski P., Hryniewicz O. Soft Methods in Hypotheses Testing. In: Ruan D., Kacprzyk J., Fedrizzi M. (Eds.) Soft computing for risk evaluation and management. Heidelberg: Physica Verlag, 2001, 55-72, http://dx.doi.org/10.1007/978-3-7908-1814-7_4.

14. Hryniewicz O. Estimation of life-time with fuzzy prior information: application in reliability. In: Kacprzyk J., Fedrizzi M. (Eds.) Combining Fuzzy Imprecision with Probabilistic Uncertainty in Decision Making. Berlin: Springer-Verlag, 1988, 307-321, http://dx.doi.org/10.1007/9783-642-46644-1_21.

15. Hryniewicz O. Possibilistic approach to Bayes statistical decisions. In: Grzegorzewski P., Hryniewicz O., Gil M.A. (Eds.) Soft methods in probability, statistics and data analysis. Heidelberg: Physica-Verlag, 2002, 207-218, http://dx.doi.org/10.1007/978-3-7908-1773-7_20.

16. Hryniewicz O. Fuzzy sets in the evaluation of reliability. In: Levitin G. (Ed.) Computational intelligence in reliability engineering. Berlin: Springer-Verlag, 2007, 363-386, http://dx.doi.org/10.1007/978-3-540-37372-8_13.

17. Kaminskiy M.P., Krivtsov V.W. A Simple procedure for Bayesian Estimation of the Weibull Distribution. IEEE Transactions on Reliability 2005; 54: 612-616, http://dx.doi.org/10.1109/TR.2005.858093.

18. Kruse R. The strong law of large numbers for fuzzy random variables. Information Sciences 1982; 28:233-241, http://dx.doi.org/10.1016/00200255(82)90049-4. 
19. Kruse R., Meyer M.D. Statistics with Vague Data. Dordrecht: D. Reidel, 1987, http://dx.doi.org/10.1007/978-94-009-3943-1.

20. Kwakernaak H. Fuzzy random variables, Part I: definitions and theorems. Information Sciences 1978; 15: 1-15, http://dx.doi.org/10.1016/00200255(78)90019-1.

21. Kwakernaak H. Fuzzy random variables, Part II: algorithms and examples for the discrete case. Information Sciences 1978; 17: 253-278, http://dx.doi.org/10.1016/0020-0255(79)90020-3.

22. Lawless J.F. Statistical models and methods for lifetime data. New York: J. Wiley and Sons, 1982.

23. Martz H.F., Waller R.A. Bayesian Reliability Analysis. New York: J. Wiley \& Sons, 1982.

24. Raiffa H., Schleifer R. Applied Statistical Decision Theory. Cambridge: The M.I.T. Press, 1961.

25. Taheri S.M., Behboodian J. A Bayesian approach to fuzzy hypotheses testing, Fuzzy Sets and Systems 2001; 123: 39-48, http://dx.doi. org/10.1016/S0165-0114(00)00134-2.

26. Tanaka H., Okuda T., Asai K. Fuzzy information and decisions in statistical model. In: Gupta M.M., Ragade R.K., Yager R.R. (Eds.) Advances in Fuzzy Sets Theory and Applications. Amsterdam: North-Holland, 1979, 303-320.

27. Viertl R. Statistical Methods for Fuzzy Data. Chichester UK: J. Wiley \& Sons, 2011, http://dx.doi.org/10.1002/9780470974414.

28. Viertl R., Hareter D. Generalized Bayes' theorem for non-precise a-priori distribution. Metrika 2004; 59: 263-273, http://dx.doi.org/10.1007/ s001840300283.

29. Zadeh L.A. Fuzzy sets as a basis for a Theory of Possibility. Fuzzy Sets and Systems 1978; 1: 3-38, http://dx.doi.org/10.1016/01650114(78)90029-5.

\author{
Olgierd HRYNIEWICZ \\ Systems Research Institute \\ and \\ Warsaw School of Information Technology \\ Newelska 6, 01-447 Warsaw, Poland \\ Katarzyna KACZMAREK \\ Piotr NOWAK \\ Systems Research Institute \\ Newelska 6, 01-447 Warsaw, Poland \\ E-mail: hryniewi@ibspan.waw.pl, \\ K.Kaczmarek@ibspan.waw.pl, Piotr.Nowak@ibspan.waw.pl
}

